\title{
Adivinhas: Quem é Quem na Tabela Periódica
}

As "Adivinhas sobre a Tabela Periódica" são uma ideia simples e popular, para ajudar os nossos alunos e demais cidadãos (interessados em Ciência) a compreender melhor alguns aspectos dos elementos da Tabela Periódica.

Só se abordam os elementos químicos de número atómico entre 1 e 20 , que são os estudados formalmente no Ensino Básico.

O jogo de "Adivinhas sobre a Tabela Periódica" está disponível on line, em http://nautilus.fis.uc.pt/cec/adivinhastp. Este aspecto parece-nos relevante para tornar o material mais aberto e disponível.

Na versão on line, há uma área de submissão de adivinhas por parte dos utilizadores. Uma vez recebidas estas colaborações externas, é apurada a sua validade pedagógica e científica. Se esta avaliação for positiva as adivinhas construídas pelos próprios utilizadores integrarão também o módulo digital.

É bom dizer, porém, que o formato de adivinhas é ainda aplicável em "versão papel", no esquema tradicional de uma adivinha ou mais, apresentadas em determinada folha e a(s) respectivas solução(ões) noutro local. As adivinhas sobre a Tabela Periódica podem ser igualmente úteis para quebrar o ritmo, porventura denso, de uma aula de química, para actividades extra-curriculares em ciência, etc.
Um jogo incluindo estas adivinhas foi apresentado e premiado no interessante e bem sucedido concurso "Tabela Periódica: um elemento em cada casa e uma casa para cada elemento", organizado pelo Instituto Superior de Engenharia do Porto e pelo Centro de Química da Universidade do Porto.

Apresentamos de seguida o conjunto das 64 adivinhas que constituem o jogo, chamando à atenção, contudo, que o efeito surpresa é maior com as adivinhas apresentadas aleatória e individualmente, ditadas ou, melhor ainda, a partir do módulo on line.

\section{Hidrogénio}

Sou o primeiro dos primeiros

E pequeno ao mundo vim

Há uma bomba muito grande

Que é uma bomba de mim...

Posso ser prótio ou deutério

E trítio, também algum

Sou de pequeno tamanho

Meu número atómico é um.

Em substância elementar

Sou um gás bem explosivo

Estou nos hidróxidos com o "O"

E aí sou abrasivo.

No sol existo imenso

Mas na água estou também

E tenho lá sempre o dobro

Do que o oxigénio tem.

\section{Hélio}

Meu número atómico é dois

Existo só, sem fazer mal

0 grupo a que pertenço

Na tabela é terminal.

0 período em que estou

É um pouco especial

Só lá moro eu e outro

E sou eu o "maioral".

Existo em dirigíveis

E ajudo-os a voar

Pois sou um gás pouco denso

Menos denso que o ar.

\section{Lítio}

Com água, dou "zaragata"

Mas como eu, há piores

Todos os outros do grupo

Dão "zaragatas" maiores.

Meu número atómico é três

Não sou abundante no mundo

Meu grupo é o primeiro

Meu período é o segundo.

Estou nas cinzas do tabaco

E nas pilhas participo

O sódio e o potássio

São maiores, mas do meu tipo.

\section{Berílio}

As esmeraldas são belas

E eu das esmeraldas sou

Só que sou também de belas

Belas comigo começou...

\footnotetext{
* Departamento de Química da FCUP, Centro de Física Computacional email: jcpaiva@fc.up.pt
} 
Meu número atómico é quatro

Mas é no dois que eu penso

Pois é dois e sempre dois

$\mathrm{O}$ período e grupo a que pertenço.

Meus sólidos são muito rígidos Aos raios $X$ são transparentes Tenho um B no meu símbolo

E segunda letra diferente.

\section{Boro}

Basta apenas uma letra

P'ra este elemento chamar

É do segundo período

E do grupo do azar.

Estou no bórax incluído

No pirex também estou

Sou um berílio sem "e"

Adivinha quem eu sou.

Meu número atómico é cinco

E sou um semi-metal

A primeira letra de "burro"

Sou mesmo eu, tal e qual.

\section{Carbono}

Chamam-me 'elemento da vida'

E têm muita razão

Onde há vida, eu lá estou

E sou o início de cão.

Pertenço ao grupo catorze

$\mathrm{E}$ ao período segundo

O diamante sou eu

Embora raro no mundo.

Usam-me para escrever

Não sou tinta permanente

Mas estou dentro do teu lápis

Assim conduzo a corrente.

\section{Azoto}

Ligado a um igual

Estás-me sempre a respirar

Eu sou até mais abundante

Que o oxigénio do ar.

Estou ligado à tua vida

Nas proteínas eu estou

Sou parte do amoníaco

Adivinha quem eu sou.

Meu gás é não reactivo

Do grupo quinze faço parte

Fixar-me nas plantinhas

É para mim uma arte.

\section{Oxigénio}

Vou até ao teu pulmão

E sou vital para ti

Se estivesses onde não estou

Já não estarias aqui...

Sou do segundo período

Ás vezes formo iões

0 grupo a que pertenço

É o dobro dos meus protões.

Sou mais denso que 0 ar

Mas dele eu faço parte

Onde houver combustiveis e eu

Podes até queimar-te.

Ando muito com um par

Mas também faço um trio

Graças a mim, lá no alto

0 planeta é mais frio.

Quando o sol ataca forte

Com a sua radiação

Eu (a três) tiro ultravioleta

Para tua protecção,

Estou na molécula da água Com o hidrogénio a ganhar Mas na água oxigenada Já ando com ele a par.

\section{Flúor}

Sou do segundo período

E do grupo dezassete

Comigo nos teus dentinhos

Nenhuma bactéria se mete.

Sou gás com o meu parzinho

E do teflon sou obreiro

Não sou só um halogéneo

Mas o halogéneo primeiro.

Quando lavas os teus dentes

É de mim que tu te cobres

$\mathrm{Na}$ tabela, depois do meu grupo

Só existe o dos nobres.

\section{Néon}

O meu grupo é o dezoito

Meu período é o segundo

Estou nas estrelas e dou luz

Posso iluminar o mundo.

Minha substância é gasosa

Não sou ferro nem cobre

Acho que sou "gente fina"

Sou o segundo e sou nobre.
Meu símbolo tem "N"grande

A ligar-me tenho ódio

Minha letra segunda é pequena

Mas meu nome não é sódio.

\section{Sódio}

Ao ar fico oxidado

Perco todo o meu brilho

Sou o onze e na água

Faço barulho e "estrilho".

Fico até aliviado

Se um electrão me escapa

Estou entalado no grupo

Pelo lítio e pelo capa.

Faço estrilho e até luz

Quando na água me meto

Estou presente nas salinas

Com o meu par cloreto.

Os impulsos nervosos

Chamam-me para passar

E posso sair dos teus olhos

Quando resolves chorar.

\section{Magnésio}

Sou do grupo segundo

E o segundo da fila

Existo nos alimentos

Estou na clorofila.

Senhoras grávidas tomam-me

E existo no agrião

Dou uma luz muito intensa

Quando estou em combustão.

Minha primeira letra é "M"

E a segunda é vogal

O meu período é o terceiro

Estou no verde vegetal.

\section{Alumínio}

Existo em janelas e portas

A bauxite é coisa minha

Estou em tachos e panelas

E em rolos, na cozinha.

Se olhares meu número atómico

E o grupo onde fui parar

Vais descobrir quem eu sou

Pois sou filho do azar! 
Na água, em abundância

Posso matar, sem pistola

Sou um metal muito dúctil

Da lata de Coca-Cola...

Devo ser árabe de raiz

Na crosta da Terra vivo bem

Algarve, Alfarroba e Alcácer

Começam por mim também.

\section{Silício}

Sou da família do carbono

Mas sou de maior tamanho

0 grupo a que pertenço

É o número atómico que tenho.

Sino, sítio e silva

São palavras da minha laia

Existo dentro do vidro

E na areia da praia.

Sou do terceiro período

Chamam-me semi-metal

Pico em folhas de urtigas

E no quartzo, sou cristal.

\section{Fósforo}

Meu símbolo não é $\mathrm{F}$

Embora o faça lembrar

$\mathrm{O}$ isqueiro é meu concorrente

P'ra ajudar a fumar...

Sou do grupo do azoto

Estou no leite e na ervilha

Comigo se fazem luzes

Foguetes de maravilha.

Meu número atómico é quinze

Estou no osso e no dente

Em fosfatos, para lavagem

Prejudico o ambiente.

\section{Enxofre}

Sou um sólido bonito

Tenho cor de omelete

Quando ando com iguais

Junto-me sempre a mais sete.

Sou um pó sólido, lindo

Não metal, amarelado

Dizem que o meu cheiro

Parece um ovo estragado.

Sou do grupo dezasseis

Desgostam dos meus odores

Saio de dentro da Terra

Em S. Miguel, nos Açores.

Estou na pólvora vulgar

Usam-me em pipas de vinho

Estou no ácido sulfúrico

Sólido, sou amarelinho.

\section{Cloro}

Sou da família do flúor

E sou um gás, normalmente

Tal como o oxigénio

Eu também sou comburente.

Estou presente na lixívia

Para a roupa branquear

Encontras-me nas piscinas

P'ra água desinfectar.

Estou no ácido clorídrico

E não sou o hidrogénio

É fácil ver onde estou

Sou o segundo halogéneo.

\section{Árgon}

Saber quem sou eu

É fácil de adivinhar

Pois meu próprio símbolo

Estás sempre a respirar.
Sou gás nobre com orgulho

0 néon é meu parceiro

O meu grupo é o último

E eu sou lá o terceiro.

Ando pela atmosfera

E não sou de me ligar

Sou um gás raro ou nobre

E eu próprio sou o ar...

\section{Potássio}

Usam-me em sabões

E sou do grupo primeiro

Moro abaixo do sódio

Acho que sou terceiro.

Um electrão de valência

Com frequência me escapa

Fico num ião positivo

Mas continuo com "capa".

Desatino com a água:

Se dentro dela mergulhado

Fico muito furioso

E bastante inflamado.

\section{Cálcio}

0 grupo a que pertenço

Não tenhamos ilusões, Tem o primeiro algarismo

Do meu número de protões.

Estou na pedra da calçada A concha, fui eu que a fiz No quadro preto eu escrevo Pois eu sou parte do giz.

Antes de mim há o magnésio E eu só venho depois

$\mathrm{Na}$ água de cal fico turvo Se me deitam "C ó dois"

Estou na cal viva presente 0 mármore é feito de mim Posso até acumular-me Como pedra no teu rim. 